\title{
The Critical Role of the Right Dorsal and Ventral Anterior Insula in Reciprocity: Evidence From the Trust and Ultimatum Games
}

\author{
Frank Krueger ${ }^{1,2 * t}$, Gabriele Bellucci ${ }^{3 \dagger}$, Pengfei $X u^{4,5,6}$ and Chunliang Feng ${ }^{7 *}$ \\ ${ }^{1}$ Department of Psychology, George Mason University, Fairfax, VA, United States, ${ }^{2}$ School of Systems Biology, George \\ Mason University, Fairfax, VA, United States, ${ }^{3}$ Max Planck Institute for Biological Cybernetics, Tübingen, Germany, \\ ${ }^{4}$ Shenzhen Key Laboratory of Affective and Social Neuroscience, Center for Brain Disorders and Cognitive Sciences, \\ Shenzhen University, Shenzhen, China, ${ }^{5}$ Center for Neuroimaging, Shenzhen Institute of Neuroscience, Shenzhen, China, \\ ${ }^{6}$ Great Bay Neuroscience and Technology Research Institute, Kwun Tong, Hong Kong, ${ }^{7}$ Guangdong Provincial Key \\ Laboratory of Mental Health and Cognitive Science, Center for Studies of Psychological Application, School of Psychology, \\ South China Normal University, Guangzhou, China
}

OPEN ACCESS

Edited by:

Jessica A. Turner

Georgia State University,

United States

Reviewed by:

Khalil Thompson,

Georgia State University,

United States

Jan B. Engelmann,

University of Amsterdam, Netherlands

*Correspondence:

Frank Krueger

FKrueger@gmu.edu

Chunliang Feng

Chunliang.Feng@m.scnu.edu.cn

†These authors have contributed equally to this work

Specialty section:

This article was submitted to Cognitive Neuroscience,

a section of the journal

Frontiers in Human Neuroscience

Received: 16 January 2020 Accepted: 20 April 2020 Published: 15 May 2020

Citation:

Krueger F, Bellucci G, Xu P and Feng C (2020) The Critical Role of the Right Dorsal and Ventral Anterior

Insula in Reciprocity: Evidence From the Trust and Ultimatum Games. Front. Hum. Neurosci. 14:176. doi: 10.3389/fnhum.2020.00176
Keywords: trust, reciprocity, insula, decision-making, network

Social norms represent a fundamental grammar of social interactions, as they refer to shared expectations about behaviors of one's social group members (Bicchieri, 1990, 2005; Santos et al., 2018). Based on these expectations, particularly accurate predictions about another person's future behavior are possible-establishing the preconditions for cooperative interactions. Overall, group prosperity is enhanced when all members comply with social norms (i.e., norm compliance). However, social norms need to be enforced by sanctioning violators (i.e., norm enforcement). For instance, expectations of compliance with a norm of reciprocity may help overcome the fear of being betrayed by a social partner. As cooperation allows for better collective solutions than those attained by self-interested individuals, social groups are interested in enforcing compliance with social norms by their members, and developing tools for successful recognition of norm violators (Fehr and Schurtenberger, 2018). Thus, a fragile balance between incentives for norm enforcement and deterrents for sanctions of violators is required for a well-functioning society.

Interactive economic games, such as the trust game (TG) (Berg et al., 1995) and the ultimatum game (UG) (Güth et al., 1982), provide reliable experimental settings for the investigation of motivational, affective, and socio-cognitive processes involved in social norm compliance and enforcement (Corradi-Dell'acqua et al., 2016; Feng et al., 2017; Engelmann et al., 2019; Krueger and Meyer-Lindenberg, 2019). Based on the learned and internalized social norms, an agent's reciprocal behavior is determined by the evaluation of the expected or experienced kindness of a partner by weighting the partner's intentions (i.e., the underlying motivation in performing an action) and the action outcomes (i.e., positive or negative consequences of an action for oneself and others) (Falk and Fischbacher, 2006).

Recent work has shown that individuals integrate this information into their beliefs about another person's character traits for reliable predictions of the other's most likely behavior in a new social interaction (Krueger et al., 2009; Bellucci et al., 2019b; Dorfman et al., 2019). Hence, reliably estimating the kindness/unkindness of a partner facilitates norm compliance (i.e., positive reciprocity) or norm enforcement (i.e., negative reciprocity) across contexts and time. Importantly, the ability to learn from feedback about a partner's intentions and action outcomes heavily hinges on the degree to which feedback information violates one's priors and expectations (Fouragnan et al., 2013; Dorfman et al., 2019; Bellucci and Park, 2020). The ability to detect expectancy violations might even counteract biases in belief updating about another person's benevolence or malevolence. 
Integrating neuroimaging data from economic games across a plethora of neuroimaging studies via coordinate-based metaanalyses (Feng et al., 2015; Bellucci et al., 2017a) —in combination with task-based and task-free functional connectivity analyses (Gurevitch et al., 2018) — has revealed the right anterior insula ( $\mathrm{R}$ $\mathrm{AI}$ ) as a candidate brain region for detection of norm deviations in trusting (i.e., trust game) and fairness-related (i.e., ultimatum game) interactions (Krueger et al., 2008; Bellucci et al., 2018). Representing a posterior-to-anterior remapping of interoceptive signals within the insular cortex, the R AI takes a crucial role in salience detection across multiple domains, whereas the posterior insular cortex mediates sensorimotor processes (Craig, 2009). Being part of the salience network (SAN), two functionally distinct brain regions within the $\mathrm{R} A \mathrm{AI}-\mathrm{a}$ dorsal $\mathrm{AI}(\mathrm{dAI})$ and ventral AI (vAI) cluster-have been identified Kelly et al., 2012; Chang et al., 2013; Wager and Barrett, 2017). Whereas the R $\mathrm{dAI}$ act as a switch that exerts direct influences on the central executive network (CEN, i.e., cognitive control system, including high-order executive functions; Seeley et al., 2007; Bressler and Menon, 2010; Menon, 2011; Sheffield et al., 2015 and the defaultmode network (DMN, i.e., social cognition system, including autobiographical memory, self-monitoring, and theory of mind; Andrews-Hanna et al., 2010; Bressler and Menon, 2010; Menon, 2011), the R vAI exerts direct influence on limbic cortices (which mediate affective processes) (Sridharan et al., 2008; Goulden et al., 2014; Uddin et al., 2014). These AI subregions-encoding a common currency of aversion-were both found consistently activated for responses to unfair behavior but differently engaged by trust and trustworthiness behaviors (Bellucci et al., 2018). In particular, the dAI was preferentially engaged by trust behavior while the vAI by trustworthiness behavior (Bellucci et al., 2018). We propose that consistent recruitment of the AI during those social behaviors is a signature of their common neural processing related to expectancy violation in the form of deviations from social norms. In particular, social behaviors in the TG and UG, such as trust in unknown partners, trustworthiness during repeated interactions and rejection of unfair offers, imply violations of two fundamental social norms - fairness and reciprocation. With this respect, they require evaluations of intentions and outcomes of actions that are aligned with individual expectations in case of compliant behaviors but that deviate from individual expectations in case of violations.

When interacting with a stranger in a one-shot TG, in which the investor interacts only once with a trustee, investors feel compelled to comply with a fairness norm and share some fair amount with the trustee. However, the probability that the trustee, whose reputation and past social behavior are supposedly unknown, betrays trust in these circumstances is not negligible. Behavioral studies have repeatedly shown that individuals in these situations worry about a hypothetical, but not much unlikely, defection to occur (Mccabe et al., 1998; Bohnet and Zeckhauser, 2004; Ashraf et al., 2006; Bohnet et al., 2008; Aimone and Houser, 2011, 2013). Individuals might hence begin prospecting to decide whether to trust, for instance, by thinking about what would be most likely that the partner thinks about compliance with a reciprocity norm, and about the reasons for which the partner would consider convenient to violate this norm-processes that likely require the recruitment of the dAI. In iterative interactions, on the contrary, individuals are likely to base their trust decisions on what they have learned from the partner over multiple encounters, switching to a more automatic, knowledge-based decision-making process involving social affiliation regions (Krueger et al., 2007). This is further consistent with the absence of AI signaling during iterative trust decisions with the same partner (Bellucci et al., 2017a).

Reciprocation of trust requires similar evaluations of normdeviant behaviors by the trustee in a multi-round TG. The concerns that investors have from a second-person perspective, trustees have those from a first-person perspective. In particular, trustees have to weigh the advantages and disadvantages of a cooperative and non-cooperative response to the investor's kind behavior. Also, as the amount of money entrusted by investors in the TG is multiplied by a predetermined factor (usually, tripled), trustees are in an advantageous situation in which defection lures with its convenience. However, defection also implies the violation of a reciprocation norm that will enforce inequality in the payoff distribution between investors and trustees. Hence, trustees might feel guilty of taking advantage of their situation and might fear of what the partner could think of them, especially in iterative interactions where future encounters loom and the importance of a good reputation is more pressing. These aversive feelings are likely encoded in the vAI. On the contrary, in circumstances of low external incentives, such as during reciprocal decisions in single interactions where concerns about what others might think and the pressure of social norm compliance are absent, cognitive control might be required to enact reciprocity. This nicely chimes with the recruitment of dorsolateral prefrontal regions during trustworthiness behavior in single and anonymous interactions (Knoch et al., 2006; Van Den Bos et al., 2011; Nihonsugi et al., 2015).

The receiver in the UG, who faces an unfair offer from the proposer, is in a situation that likely elicits similar psychological processes to those evoked by both investors' and trustees' concerns in the TG. On the one hand, the receiver is confronted with an actual violation of the fairness norm perpetrated by the proposer who sent an unfair offer. Unfair offers elicit negative feelings (e.g., increases in skin conductance activity) in receivers who respond by rejecting the offer. Since the unfair offer implies an actual inequal outcome in resource distributions (given that unfair offers are generally lower than one-third of the resources available to proposers), the receiver might be concerned about the inequality derived from the norm violation. Outcome inequality might hence evoke negative feelings in the receiver that support negative reciprocity via recruitment of the vAI. On the other hand, however, high rejection rates and increased skin conductance activity have been observed only for unfair offers proposed by a human partner, but not for unfair offers generated by computers (Sanfey et al., 2003; Van 'T Wout et al., 2006). These results suggest that the receiver in the UG is further concerned about the intentions of the proposer and is determined to forgo immediate benefits to enforce a fairness norm via a rejection of the offer, which likely recruits the dAI. 
Hence, consistent activations of the AI in all these behaviors likely refer to general signaling of violations of expectations about actions that deviate from social norms. However, given the different activation patterns of the dAI and vAI, we here propose an overarching framework in which the $\mathrm{R} A I-$ part of the salience network (SAN)-recruits other large-scale brain networks to determine the appropriate reciprocal behavior (via the central-executive network, CEN) based on evaluations about the partner's kindness (via the default-mode network, DMN) (Krueger and Hoffman, 2016; Bellucci et al., 2019a). Hereby, the R AI subregions play a crucial role in signaling how a deviation has occurred, in particular, because of an intentional action ( $R$ dAI) or due to an action outcome (R vAI; Figure 1).

We propose that the SAN detects (vAI) and generates an aversive experience based on the salience of the social norm violation and provides an emotional signal (amygdala) encoding the severity of outcome related to the norm violation (Buckholtz et al., 2008). The DMN anchored in the medial prefrontal cortex (mPFC) integrates the outcome (via the ventromedial PFC's inter-network connectivity with SAN) and the intention (via the dorsomedial PFC's intra-network connectivity with the temporoparietal junction, TPJ) of the norm violation into an assessment of kindness (Krueger et al., 2009). The CEN anchored in lateral PFC (IPFC) converts the kindness signal from the DMN into an appropriate reciprocal behavior that fits the norm violation. Previous work has demonstrated that connectivity between the MPFC and IPFC was associated with evaluations of norm violations for appropriate punishment decisions (Bellucci et al., 2017b).

Therefore, in the social settings of the economic paradigms here considered, the vAI likely represents forms of violations of an expected outcome such as outcome inequalities (i.e., less- vs.

\section{RECIPROCITY = KINDNESS (INTENTION + OUTCOME)}

\begin{tabular}{|c|c|c|c|c|}
\hline RECIPROCITY & $\begin{array}{c}\text { NEGATIVE } \\
\text { RECIPROCITY }\end{array}$ & & $\begin{array}{c}\text { POSITIVE } \\
\text { RECIPROCITY }\end{array}$ & CEN: IPFC \\
\hline KINDNESS & UNKINDNESS & & KINDNESS & DMN: mPFC \\
\hline $\begin{array}{l}\text { INTENTION } \\
\text { (I) }\end{array}$ & $\begin{array}{c}\begin{array}{c}\text { Actual } \\
\text { Retrospective }\end{array} \\
\begin{array}{c}\text { Attribution of } \\
\text { Bad Intention } \\
\left(\mathrm{I}^{-}\right)\end{array}\end{array}$ & $\begin{array}{l}\text { Favorable Intention } \\
\qquad \begin{array}{l}\text { Betrayal } \\
\text { PI dAI }\end{array}\end{array}$ & $\begin{array}{l}\text { Hypothetical } \\
\text { Prospective } \\
\begin{array}{c}\text { Inferrence of } \\
\text { Good Intention } \\
\left(\mathrm{I}^{+}\right)\end{array}\end{array}$ & SAN: dAI \\
\hline $\begin{array}{l}\text { OUTCOME } \\
\text { (O) }\end{array}$ & $\begin{array}{c}\begin{array}{c}\text { Anger based on } \\
\text { Negative Outcome } \\
\left(\mathrm{O}^{-}\right)\end{array} \\
\frac{\text { Disadvantageous }}{\text { Less }}\end{array}$ & $\begin{array}{c}\underline{\text { Inequality }} \\
\text { Equal Outcome }\end{array}$ & $\begin{array}{c}\begin{array}{c}\text { Guilt based on } \\
\text { Positive Outcome } \\
\left(\mathrm{O}^{+}\right)\end{array} \\
\frac{\text { Advantageous }}{\text { More }}\end{array}$ & SAN: vAI \\
\hline $\begin{array}{l}\text { SOCIAL } \\
\text { NORM }\end{array}$ & $\frac{\text { NORM }}{\text { ENFORCEMENT }}$ & $\frac{\text { AVERSION }}{\text { DEVIATION }}$ & $\frac{\text { NORM }}{\text { COMPLIANCE }}$ & $\begin{array}{c}\text { BRAIN } \\
\text { NETWORK }\end{array}$ \\
\hline
\end{tabular}

FIGURE 1 | Framework: Role of R dAl and R vAl in Reciprocity. Based on social norms, an agent's reciprocal behavior is determined by evaluating the expected or experienced kindness/unkindness of a partner's normative action: the intention as the underlying motivation and the outcome as the consequence of the action. The $\mathrm{R}$ Al (part of SAN) recruits other large-scale networks to determine the appropriate reciprocity (e.g., IPFC via CEN) based on kindness evaluations (e.g., mPFC via DMN). The R Al subregions play a crucial role in signaling deviations from expectations on outcomes (R vAl) and intentions (R dAl) of an action, facilitating norm compliance (positive reciprocity), and norm enforcement (negative reciprocity). The vAl signals violations of expected outcomes (disadvantageous vs. advantageous outcome inequality) that elicit aversive feelings (anger vs. guilt). The dAl signals violations of expected intentional behaviors (actual vs. hypothetical betrayal) that evoke social-cognitive processes (attribution vs. inference) [Note that brain image adopted from Uddin (2015)]. R, right; SAN, Salience Network; PI, Posterior Insula; Al, Anterior Insula; vAl, Ventral Anterior Insula; dAI, Dorsal Anterior Insula; DMN, Default-mode Network; mPFC, Medial Prefrontal Cortex; CEN, Central-executive Network, IPFC, Lateral Prefrontal Cortex; O+, Positive Outcome; O-, Negative Outcome; I-, Negative Intention; I+, Positive Intention. 
more-than-equal) that elicit negative feelings via co-activation of the limbic network (e.g., amygdala). In particular, less-thanequal outcomes refer to a situation of disadvantageous inequality that triggers negative feelings such as anger and envy (due to a negative outcome for the self), which support norm enforcement in the form of negative reciprocity (e.g., punishment). On the contrary, more-than-equal outcomes refer to situations of advantageous inequality that likely triggers different negative feelings such as guilt (due to a positive outcome for the self), which compel to norm compliance in the form of positive reciprocity (e.g., cooperation).

The dAI, instead, likely represents forms of violations of an expected intentional behavior such as betrayal (both actual and hypothetical) that elicit social-cognitive processes via coactivation of the default-mode network. In particular, actual deviant behaviors prompt to retrospection on the intentionally perpetrated betrayal that triggers socio-cognitive processes such as attribution of bad intentions, thereby promoting norm enforcement in the form of negative reciprocity (e.g., punishment). On the contrary, hypothetical deviant behaviors prompt to prospection on a possible intentional betrayal that triggers socio-cognitive processes such as inferences on the other's intentions, thereby supporting norm compliance in the form of positive reciprocity (e.g., trust).

Given the proposed neuropsychological model, some predictions for other recently reported activation patterns associated with social normative behaviors are possible. For instance, social interactions in which some form of expectancy violation is involved might require recruitment of the AI. For the classical Prisoner's Dilemma game, where two players can decide to cooperate or betray each other, both partiesacting in their own self-interests-choose often to protect themselves at the expense of the other player; thereby, producing the worst outcome for both parties by non-reciprocation of cooperation (Peterson, 2015). A neuroimaging study employing an iterated version of the Prisoner's Dilemma game showed greater activation in $\mathrm{R}$ dAI during unreciprocated compared to reciprocated cooperation when both players were informed about the outcome of each trial game (but not during their decisions) (Rilling et al., 2008). Another study revealed that depressed compared to healthy individuals reported higher levels of negative feelings (i.e., betrayal, guilt) during this game. Across all players, the R vAI was more activated comparing outcomes, where one of the players cooperated and the other defected, with outcomes, where both players either cooperated or defected (Gradin et al., 2016).

Further, shame and embarrassment, which emerge from the recognition that one's behavior diverges from a group's expectancies, should elicit activations in the AI. Preliminary evidence aligns with this prediction and suggests that shame and embarrassment elicit activations particularly in the vAI,

\section{REFERENCES}

Aimone, J. A., and Houser, D. (2011). Beneficial betrayal aversion. PLoS ONE 6:e17725. doi: 10.1371/journal.pone.0017725 consistently with the fact that these negative feelings are based on violations caused by the consequences (and not the intentions) of one's behavior (Muller-Pinzler et al., 2015; Zhu et al., 2019). Similarly, punishment and blame, which rely on the recognition of another's deviant behavior, should recruit the AI as well. Previous evidence chimes with this prediction, pointing specifically to the dAI, consistently with the fact that punishment and blame require socio-cognitive processes for understanding reasons and motives of another's wrongdoing (Krueger and Hoffman, 2016; Patil et al., 2017; Bellucci et al., 2020). On the contrary, other social behaviors such as generosity or altruism should activate the AI only if they also involve expectancy violations. Previous work on these behaviors seems to confirm such prediction (Moll et al., 2006; Coll et al., 2017; Karns et al., 2017), showing AI activations only when a form of expectancy violation is involved such as when helping an offender or breaking a promise to cooperate (Baumgartner et al., 2009; David et al., 2017).

Taken together, the AI is an underestimated but essential brain region for understanding human social cognition and its pathophysiological forms in social brain disorders such as schizophrenia and autism (Namkung et al., 2017). Our framework provides a distinctive mapping of the $\mathrm{R}$ AI subdivisions that can be employed in future multimodal neuroimaging studies to test hypotheses on the AI functioning in reciprocity. For this reason, our neuropsychological framework contributes to a more comprehensive understanding of this region for basic and clinical neuroscience in which altered processing in AI subdivisions determine different aspects of prevalent brain disorders (e.g., psychosis, autism).

\section{AUTHOR CONTRIBUTIONS}

FK and CF prepared the first draft of the article. All authors contributed to the final version.

\section{FUNDING}

PX was supported by the National Natural Science Foundation of China (31871137), Young Elite Scientists Sponsorship Program by China Association for Science and Technology (2018), Guangdong Pearl River Talents Plan Innovative and Entrepreneurial Team grant (2016ZT06S220), Shenzhen Science and Technology Research Funding Program (JCYJ20180507183500566), and Shenzhen Peacock Program (827-000235, KQTD2015033016104926). CF was supported by the funding from the National Natural Science Foundation of China (31900757). FK was supported by the Air Force Office of Scientific Research (FA955018-1-0455).
Aimone, J. A., and Houser, D. (2013). Harnessing the benefits of betrayal aversion. J. Economic Behav. Organiz. 89, 1-8. doi: 10.1016/j.jebo.2013.02.001

Andrews-Hanna, J. R., Reidler, J. S., Sepulcre, J., Poulin, R., and Buckner, R. L. (2010). Functional-anatomic fractionation of the brain's 
default network. Neuron 65, 550-562. doi: 10.1016/j.neuron.2010. 02.005

Ashraf, N., Bohnet, I., and Piankov, N. (2006). Decomposing trust and trustworthiness. Exp. Econom. 9, 193-208. doi: 10.1007/s10683-006-9122-4

Baumgartner, T., Fischbacher, U., Feierabend, A., Lutz, K., and Fehr, E. (2009). The neural circuitry of a broken promise. Neuron 64, 756-770. doi: 10.1016/j.neuron.2009.11.017

Bellucci, G., Camilleri, J. A., Iyengar, V., Eickhoff, S. B., and Krueger, F. (2020). The emerging neuroscience of social punishment: meta-analytic evidence. Neurosci. Biobehav. Rev. 6:e1000097. doi: 10.1016/j.neubiorev.2020.04.011

Bellucci, G., Chernyak, S., Hoffman, M., Deshpande, G., Dal Monte, O., Knutson, K. M., et al. (2017b). Effective connectivity of brain regions underlying third-party punishment: functional MRI and Granger causality evidence. Soc. Neurosci. 12, 124-134. doi: 10.1080/17470919.2016.1153518

Bellucci, G., Chernyak, S. V., Goodyear, K., Eickhoff, S. B., and Krueger, F. (2017a). Neural signatures of trust in reciprocity: a coordinate-based meta-analysis. Hum Brain Mapp 38, 1233-1248. doi: 10.1002/hbm.23451

Bellucci, G., Feng, C., Camilleri, J., Eickhoff, S. B., and Krueger, F. (2018). The role of the anterior insula in social norm compliance and enforcement: evidence from coordinate-based and functional connectivity meta-analyses. Neurosci. Biobehav. Rev. 92, 378-389. doi: 10.1016/j.neubiorev.2018.06.024

Bellucci, G., Hahn, T., Deshpande, G., and Krueger, F. (2019a). Functional connectivity of specific resting-state networks predicts trust and reciprocity in the trust game. Cogn. Affect. Behav. Neurosci. 19, 165-176. doi: 10.3758/s13415-018-00654-3

Bellucci, G., Molter, F., and Park, S. Q. (2019b). Neural representations of honesty predict future trust behavior. Nat. Commun. 10:5184. doi: 10.1038/s41467-019-13261-8

Bellucci, G., and Park, S. Q. (2020). Honesty biases trustworthiness impressions. J. Exp. Psychol. Gen. doi: 10.1037/xge0000730. [Epub ahead of print].

Berg, J., Dickhaut, J., and Mccabe, K. (1995). Trust, reciprocity, and social history. Games Economic Behav. 10, 122-142. doi: 10.1006/game.1995.1027

Bicchieri, C. (1990). Norms of cooperation. Ethics 100, 838-861. doi: $10.1086 / 293237$

Bicchieri, C. (2005). The Grammar of Society: The Nature and Dynamics of Social Norms. Cambridge: Cambridge University Press.

Bohnet, I., Greig, F., Herrmann, B., and Zeckhauser, R. (2008). Betrayal aversion: evidence from Brazil, China, Oman, Switzerland, Turkey, and the United States. Am. Economic Rev. 98, 294-310. doi: 10.1257/aer.98.1.294

Bohnet, I., and Zeckhauser, R. (2004). Trust, risk and betrayal. J. Economic Behav. Organization 55, 467-484. doi: 10.1016/j.jebo.2003.11.004

Bressler, S. L., and Menon, V. (2010). Large-scale brain networks in cognition: emerging methods and principles. Trends Cogn. Sci. 14, 277-290. doi: 10.1016/j.tics.2010.04.004

Buckholtz, J. W., Asplund, C. L., Dux, P. E., Zald, D. H., Gore, J. C., Jones, O. D., et al. (2008). The neural correlates of third-party punishment. Neuron 60 , 930-940. doi: 10.1016/j.neuron.2008.10.016

Chang, L. J., Yarkoni, T., Khaw, M. W., and Sanfey, A. G. (2013). Decoding the role of the insula in human cognition: functional parcellation and large-scale reverse inference. Cereb. Cortex 23, 739-749. doi: 10.1093/cercor/bhs065

Coll, M. P., Gregoire, M., Eugene, F., and Jackson, P. L. (2017). Neural correlates of prosocial behavior towards persons in pain in healthcare providers. Biol. Psychol. 128, 1-10. doi: 10.1016/j.biopsycho.2017.06.005

Corradi-Dell'acqua, C., Tusche, A., Vuilleumier, P., and Singer, T. (2016). Cross-modal representations of first-hand and vicarious pain, disgust and fairness in insular and cingulate cortex. Nat. Commun. 7:10904. doi: $10.1038 /$ ncomms 10904

Craig, A. D. (2009). How do you feel-now? The anterior insula and human awareness. Nat. Rev. Neurosci. 10, 59-70. doi: 10.1038/nrn2555

David, B., Hu, Y., Kruger, F., and Weber, B. (2017). Other-regarding attention focus modulates third-party altruistic choice: An fMRI study. Sci. Rep. 7:43024. doi: $10.1038 /$ srep 43024

Dorfman, H. M., Bhui, R., Hughes, B. L., and Gershman, S. J. (2019). Causal inference about good and bad outcomes. Psychol. Sci. 30, 516-525. doi: $10.1177 / 0956797619828724$

Engelmann, J. B., Meyer, F., Ruff, C. C., and Fehr, E. (2019). The neural circuitry of affect-induced distortions of trust. Sci. Adv. 5:eaau3413. doi: 10.1126/sciadv.aau3413
Falk, A., and Fischbacher, U. (2006). A theory of reciprocity. Games Economic Behav. 54, 293-315. doi: 10.1016/j.geb.2005.03.001

Fehr, E., and Schurtenberger, I. (2018). Normative foundations of human cooperation. Nat. Hum. Behav. 2, 458-468. doi: 10.1038/s41562-018-0385-5

Feng, C., Azarian, B., Ma, Y., Feng, X., Wang, L., Luo, Y. J., et al. (2017). Mortality salience reduces the discrimination between in-group and out-group interactions: a functional MRI investigation using multi-voxel pattern analysis. Hum. Brain Mapp. 38, 1281-1298. doi: 10.1002/hbm.23454

Feng, C., Luo, Y.-J., and Krueger, F. (2015). Neural signatures of fairness-related normative decision making in the ultimatum game: a coordinate-based metaanalysis. Hum. Brain Mapping 36, 591-602. doi: 10.1002/hbm.22649

Fouragnan, E., Chierchia, G., Greiner, S., Neveu, R., Avesani, P., and Coricelli, G. (2013). Reputational priors magnify striatal responses to violations of trust. J. Neurosci. 33, 3602-3611. doi: 10.1523/JNEUROSCI.3086-12.2013

Goulden, N., Khusnulina, A., Davis, N. J., Bracewell, R. M., Bokde, A. L., Mcnulty, J. P., et al. (2014). The salience network is responsible for switching between the default mode network and the central executive network: replication from DCM. Neuroimage 99, 180-190. doi: 10.1016/j.neuroimage.2014.05.052

Gradin, V. B., Perez, A., Macfarlane, J. A., Cavin, I., Waiter, G., Tone, E. B., et al. (2016). Neural correlates of social exchanges during the Prisoner's Dilemma game in depression. Psychol. Med. 46, 1289-1300. doi: $10.1017 /$ S0033291715002834

Gurevitch, J., Koricheva, J., Nakagawa, S., and Stewart, G. (2018). Metaanalysis and the science of research synthesis. Nature 555, 175-182. doi: 10.1038 /nature 25753

Güth, W., Schmittberger, R., and Schwarze, B. (1982). An experimental analysis of ultimatum bargaining. J. Economic Behav. Organiz. 3, 367-388. doi: 10.1016/0167-2681(82)90011-7

Karns, C. M., Moore, W. E. III., and Mayr, U. (2017). The cultivation of pure altruism via gratitude: a functional MRI study of change with gratitude practice. Front. Hum. Neurosci. 11:599. doi: 10.3389/fnhum.2017.00599

Kelly, C., Toro, R., Di Martino, A., Cox, C. L., Bellec, P., Castellanos, F. X., et al. (2012). A convergent functional architecture of the insula emerges across imaging modalities. Neuroimage 61, 1129-1142. doi: 10.1016/j.neuroimage.2012.03.021

Knoch, D., Pascual-Leone, A., Meyer, K., Treyer, V., and Fehr, E. (2006). Diminishing reciprocal fairness by disrupting the right prefrontal cortex. Science 314, 829-832. doi: 10.1126/science.1129156

Krueger, F., Barbey, A. K., and Grafman, J. (2009). The medial prefrontal cortex mediates social event knowledge. Trends Cognitive Sci. 13, 103-109. doi: $10.1016 /$ j.tics.2008.12.005

Krueger, F., Grafman, J., and Mccabe, K. (2008). Neural correlates of economic game playing. Philos. Trans. R Soc. Lond. B Biol. Sci. 363, 3859-3874. doi: $10.1098 /$ rstb.2008.0165

Krueger, F., and Hoffman, M. (2016). The emerging neuroscience of third-party punishment. Trends Neurosci. 39, 499-501. doi: 10.1016/j.tins.2016.06.004

Krueger, F., Mccabe, K., Moll, J., Kriegeskorte, N., Zahn, R., Strenziok, M., et al. (2007). Neural correlates of trust. Proc. Natl. Acad. Sci. U.S.A. 104, 20084-20089. doi: 10.1073/pnas.0710103104

Krueger, F., and Meyer-Lindenberg, A. (2019). Toward a model of interpersonal trust drawn from neuroscience, psychology, and economics. Trends Neurosci. 42, 92-101. doi: 10.1016/j.tins.2018.10.004

Mccabe, K. A., Rassenti, S. J., and Smith, V. L. (1998). Reciprocity, trust, and payoff privacy in extensive form bargaining. Games Econ. Behav. 24, 10-24. doi: 10.1006/game.1998.0638

Menon, V. (2011). Large-scale brain networks and psychopathology: a unifying triple network model. Trends Cogn. Sci. 15, 483-506. doi: 10.1016/j.tics.2011.08.003

Moll, J., Krueger, F., Zahn, R., Pardini, M., De Oliveira-Souza, R., and Grafman, J. (2006). Human fronto-mesolimbic networks guide decisions about charitable donation. Proc. Natl. Acad. Sci. U.S.A. 103, 15623-15628. doi: $10.1073 /$ pnas. 0604475103

Muller-Pinzler, L., Gazzola, V., Keysers, C., Sommer, J., Jansen, A., Frassle, S., et al. (2015). Neural pathways of embarrassment and their modulation by social anxiety. Neuroimage 119, 252-261. doi: 10.1016/j.neuroimage.2015.06.036

Namkung, H., Kim, S. H., and Sawa, A. (2017). The insula: an underestimated brain area in clinical neuroscience, psychiatry, and neurology. Trends Neurosci. 40, 200-207. doi: 10.1016/j.tins.2017.02.002 
Nihonsugi, T., Ihara, A., and Haruno, M. (2015). Selective increase of intention-based economic decisions by noninvasive brain stimulation to the dorsolateral prefrontal cortex. J. Neurosci. 35, 3412-3419. doi: 10.1523/JNEUROSCI.3885-14.2015

Patil, I., Calo, M., Fornasier, F., Cushman, F., and Silani, G. (2017). The behavioral and neural basis of empathic blame. Sci. Rep. 7:5200. doi: 10.1038/s41598-017-05299-9

Peterson, M. (2015). The Prisoner's Dilemma. Cambridge: Cambridge University Press.

Rilling, J. K., Goldsmith, D. R., Glenn, A. L., Jairam, M. R., Elfenbein, H. A., Dagenais, J. E., et al. (2008). The neural correlates of the affective response to unreciprocated cooperation. Neuropsychologia 46, 1256-1266. doi: 10.1016/j.neuropsychologia.2007.11.033

Sanfey, A. G., Rilling, J. K., Aronson, J. A., Nystrom, L. E., and Cohen, J. D. (2003). The neural basis of economic decision-making in the Ultimatum Game. Science 300, 1755-1758. doi: 10.1126/science. 1082976

Santos, F. P., Santos, F. C., and Pacheco, J. M. (2018). Social norm complexity and past reputations in the evolution of cooperation. Nature 555, 242-245. doi: $10.1038 /$ nature25763

Seeley, W. W., Menon, V., Schatzberg, A. F., Keller, J., Glover, G. H., Kenna, H., et al. (2007). Dissociable intrinsic connectivity networks for salience processing and executive control. J. Neurosci. 27, 2349-2356. doi: 10.1523/JNEUROSCI.5587-06.2007

Sheffield, J. M., Repovs, G., Harms, M. P., Carter, C. S., Gold, J. M., Macdonald, A. W. III, Daniel Ragland, J., et al. (2015). Fronto-parietal and cingulo-opercular network integrity and cognition in health and schizophrenia. Neuropsychologia 73, 82-93. doi: 10.1016/j.neuropsychologia.2015.05.006

Sridharan, D., Levitin, D. J., and Menon, V. (2008). A critical role for the right fronto-insular cortex in switching between central-executive and default-mode networks. Proc. Natl. Acad. Sci. U.S.A. 105, 12569-12574. doi: $10.1073 /$ pnas.0800005105
Uddin, L. Q. (2015). Salience processing and insular cortical function and dysfunction. Nat. Rev. Neurosci. 16, 55-61. doi: 10.1038/nrn3857

Uddin, L. Q., Kinnison, J., Pessoa, L., and Anderson, M. L. (2014). Beyond the tripartite cognition-emotion-interoception model of the human insular cortex. J. Cogn. Neurosci. 26, 16-27. doi: 10.1162/jocn_a_00462

Van Den Bos, W., Van Dijk, E., Westenberg, M., Rombouts, S. A., and Crone, E. A. (2011). Changing brains, changing perspectives: the neurocognitive development of reciprocity. Psychol. Sci. 22, 60-70. doi: $10.1177 / 0956797610391102$

Van 'T Wout, M., Kahn, R. S., Sanfey, A. G., and Aleman, A. (2006). Affective state and decision-making in the Ultimatum Game. Exp. Brain Res. 169, 564-568. doi: 10.1007/s00221-0060346-5

Wager, T. D., and Barrett, L. F. (2017). From affect to control: functional specialization of the insula in motivation and regulation. doi: 10.1101/102368

Zhu, R., Feng, C., Zhang, S., Mai, X., and Liu, C. (2019). Differentiating guilt and shame in an interpersonal context with univariate activation and multivariate pattern analyses. Neuroimage 186, 476-486. doi: 10.1016/j.neuroimage.2018.11.012

Conflict of Interest: The authors declare that the research was conducted in the absence of any commercial or financial relationships that could be construed as a potential conflict of interest.

Copyright (c) 2020 Krueger, Bellucci, Xu and Feng. This is an open-access article distributed under the terms of the Creative Commons Attribution License (CC BY). The use, distribution or reproduction in other forums is permitted, provided the original author(s) and the copyright owner(s) are credited and that the original publication in this journal is cited, in accordance with accepted academic practice. No use, distribution or reproduction is permitted which does not comply with these terms. 